\title{
Commentary Are platelets a 'forgotten' source of sepsis-induced myocardial depressing factor(s)?
}

\author{
Alexandre Mebazaa
}

Department of Anesthesiology and Critical Care Medicine, Lariboisiere Hospital, University Paris Diderot Paris 7, AP-HP, 2 Rue Ambroise Paré, 75010 Paris, France

Corresponding author: Alexandre Mebazaa, alexandre.mebazaa@Irb.aphp.paris

Published: 23 January 2008

Critical Care 2008, 12:110 (doi:10.1186/cc6220)

This article is online at http://ccforum.com/content/12/1/110

(C) 2008 BioMed Central Ltd

See related research by Azevedo et al., http://ccforum.com/content/11/6/R120

\begin{abstract}
The mechanism of sepsis-induced cardiac failure was initially thought to be related to the presence of 'myocardial depressant' substances that directly alter heart function. Exosomes released by platelets and identified in the plasma are suggested to, at least partially, explain myocardial depression in sepsis. This hypothesis needs to be evaluated by clinical studies.
\end{abstract}

Sepsis-induced cardiac dysfunction has been known for many years but the mechanism appears to be complex, including both 'intrinsic' cardiomyopathy and direct and/or indirect effects of circulating depressing factors. Among these factors, many cytokines have been suggested to play a role. In the previous issue of Critical Care, exosomes released by platelets were also suggested to play a role [1].

The clue for the sepsis-induced cardiac dysfunction in patients with septic shock came from Parker and colleagues' study in 1984 [2]. Using simultaneous radionuclide cardiac imaging and thermodilution cardiac output studies on patients with septic shock, they showed a 'paradox': all patients had a high cardiac output and maintained a stroke volume index associated with a depressed left ventricular ejection fraction <0.45. Interestingly, survivors had a left ventricular ejection fraction that remained low for 4 days and then rose to normal values within 7-10 days [2]. These data reflecting left ventricular dysfunction but also right ventricular dysfunction were confirmed by further studies $[3,4]$.

It is now agreed that systolic function deteriorates in the early phase of septic shock in humans, as confirmed by echocardiographic studies. The question of left ventricular diastolic dysfunction in septic shock remains less clearly defined. Reduced compliance manifested as reduced rapidity of ventricular filling has been described in patients with septic shock. Using left ventricular pressure-volume loops, we recently confirmed a reduced rate of left ventricular relaxation and decreased compliance in lipopolysaccharide-treated rabbits. Both alterations can be restored, at least partially, by levosimendan but not by milrinone or dobutamine [5].

In the 1970s and 1980s, the mechanism of sepsis-induced cardiac failure was thought to be the presence of 'myocardial depressant' substances that directly alter heart function [6]. Parrillo and colleagues suggested the existence of 'circulating myocardial depressant factor(s)' in humans by showing that serum obtained during the initial phase of septic shock decreased both the amplitude and the velocity of shortening of cardiomyocytes from newborn rats. Although cytokines such as TNF $\alpha$ and IL-1 $\beta$ have been suggested to be those 'circulating myocardial depressant factor(s)' and might explain a myocardial depressant activity in the first 2 days of sepsis, they can hardly explain a delayed and depressant effect on heart contractility observed 7-10 days later since $\mathrm{TNF} \alpha$ and IL-1 $\beta$ plasma levels return to normal values within 48 hours of sepsis onset.

In the study published in the current issue of the journal, Azevedo and coworkers suggest that exosomes released by platelets and identified in the plasma might explain myocardial depression in sepsis [1]. Although these results should be confirmed by different groups in different settings, it is interesting to mention that this paper opens our eyes to a new concept that platelets may release, over days, exosomes that induce and maintain alterations of heart function in septic patients. It is interesting to mention that the duration of myocardial depression corresponds to the 10 days of life of the platelets. Is this by chance or do the platelets present at

$\mathrm{IL}=$ interleukin; $\mathrm{TNF}=$ tumor necrosis factor. 
the time of sepsis insult keep a footprint of the first injury for the remaining days of their life?

Exosomes might act via free radical release [1]. Nitric oxide, produced mainly by inducible nitric oxide synthase 2 , is involved in vascular dysfunction both in animals and humans [7]. Nitric oxide plays also a crucial role in the development of the 'intrinsic' septic cardiomyopathy in many ways, including a change in contraction, protein nitration and an alteration in mitochondrial respiration [8]. In septic patients, nitric oxide produced in large amounts may interact with the superoxide anion and produce peroxynitrite. As suggested by our model of muscle dysfunction in septic patients, peroxynitrite - rather than nitric oxide per se - decreases muscle contractility [9]. Of interest, we recently showed in an animal model of sepsis that other cardiovascular mediators, such as prostaglandins and endothelin, released by cardiac endothelium, may contribute to restore cardiac contractile performance [10]. Azevedo and coworkers suggested that platelets might also be the source of these mediators [1].

In summary, platelets might be a forgotten source of mediators that alter heart function during sepsis. Many questions are raised by Azevedo and coworkers' article [1]. Are the vessels as altered as the heart by the exosomes? Does the thrombocytopenia observed in sepsis influence the amplitude of those alterations? These questions need to be evaluated by clinical studies.

\section{Competing interests}

The author declares that they have no competing interests.

\section{References}

1. Azevedo LCP, Janiszewski M, Pontieri V, Pedro MA, Bassi $E$ Tucci PJF, Laurindo FRM: Platelet-derived exosomes from septic shock patients induce myocardial dysfunction. Crit Care 2007, 11:R120.

2. Parker MM, Shelhamer JH, Bacharach SL, Green MV, Natanson C, Frederick TM, Damske BA, Parrillo JE: Profound but reversible myocardial depression in patients with septic shock. Ann Intern Med 1984, 100:483-490.

3. Natanson C, Danner RL, Elin RJ, Hosseini JM, Peart KW, Banks SM, MacVittie TJ, Walker RI, Parrillo JE: Role of endotoxemia in cardiovascular dysfunction and mortality. Escherichia coli and Staphylococcus aureus challenges in a canine model of human septic shock. J Clin Invest 1989, 83:243-251.

4. Natanson C, Eichenholz PW, Danner RL, Eichacker PQ, Hoffman WD, Kuo GC, Banks SM, MacVittie TJ, Parrillo JE: Endotoxin and tumor necrosis factor challenges in dogs simulate the cardiovascular profile of human septic shock. J Exp Med 1989, 169: 823-832.

5. Barraud D, Faivre V, Damy T, Welschbillig S, Gayat E, Heymes C, Payen D, Shah AM, Mebazaa A: Levosimendan restores both systolic and diastolic cardiac performance in lipopolysaccharide-treated rabbits: comparison with dobutamine and milrinone. Crit Care Med 2007, 35:1376-1382.

6. Parrillo JE, Burch C, Shelhamer JH, Parker MM, Natanson C, Schuette W: A circulating myocardial depressant substance in humans with septic shock. Septic shock patients with a reduced ejection fraction have a circulating factor that depresses in vitro myocardial cell performance. J Clin Invest 1985, 76:1539-1553.

7. Rabuel C, Mebazaa A: Septic shock: a heart story since the 1960s. Intensive Care Med 2006, 32:799-807.
8. Jozefowicz E, Brisson H, Rozenberg S, Mebazaa A, Gelé P, Callebert J, Lebuffe G, Vallet B, Bordet R, Tavernier B: Activation of peroxisome proliferator-activated receptor-alpha by fenofibrate prevents myocardial dysfunction during endotoxemia in rats. Crit Care Med 2007, 35:856-863.

9. Cunnion RE, Schaer GL, Parker MM, Natanson C, Parrillo JE: The coronary circulation in human septic shock. Circulation 1986, 73:637-644.

10. Mebazaa A, De Keulenaer GW, Paqueron X, Andries LJ, Ratajczak P, Lanone S, Frelin C, Longrois D, Payen D, Brutsaert DL, Sys SU: Activation of cardiac endothelium as a compensatory component in endotoxin-induced cardiomyopathy: role of endothelin, prostaglandins, and nitric oxide. Circulation 2001, 104:3137-3144. 